\title{
Solvent for [Product Name] Dosage Form
}

National Cancer Institute

\section{Source}

National Cancer Institute. Solvent for IProduct Namel Dosage Form. NCI Thesaurus.

Code C149940.

Liquid preparation consisting of an excipient that contains no active substances itself but is intended to be used in the preparation of a pharmaceutical product, e.g. for diluting/dissolving/dispersing the item(s) containing the active substance(s). 